\title{
BMJ Open Citation impact and social media visibility of Great Barrington and John Snow signatories for COVID-19 strategy
}

\author{
John P loannidis (B)
}

To cite: Ioannidis JP. Citation impact and social media visibility of Great Barrington and John Snow signatories for COVID-19 strategy. BMJ Open 2022;12:e052891. doi:10.1136/ bmjopen-2021-052891

- Prepublication history for this paper is available online. To view these files, please visit the journal online (http://dx.doi org/10.1136/bmjopen-2021 052891).

Received 28 April 2021 Accepted 25 January 2022

Check for updates

(C) Author(s) (or their employer(s)) 2022. Re-use permitted under CC BY-NC. No commercial re-use. See rights and permissions. Published by BMJ.

Departments of Medicine, of Epidemiology and Population Health, of Biomedical Data Science, and of Statistics, Stanford University, Stanford, California, USA

Correspondence to Dr John P loannidis; jioannid@stanford.edu

\section{ABSTRACT}

Objective The Great Barrington Declaration (GBD) and the John Snow Memorandum (JSM), each signed by numerous scientists, have proposed hotly debated strategies for handling the COVID-19 pandemic. The current analysis aimed to examine whether the prevailing narrative that GBD is a minority view among experts is true.

Methods The citation impact and social media presence of the key GBD and JSM signatories was assessed. Citation data were obtained from Scopus using a previously validated composite citation indicator that incorporated also coauthorship and author order and ranking was against all authors in the same ScienceMetrix scientific field with at least five full papers. Random samples of scientists from the longer lists of signatories were also assessed. The number of Twitter followers for al key signatories was also tracked.

Results Among the 47 key GBD signatories, 20, 19 and 21, respectively, were top-cited authors for career impact, recent single-year (2019) impact or either. For comparison, among the 34 key JSM signatories, 11 , 14 and 15, respectively, were top cited. Key signatories represented 30 different scientific fields $(9$ represented in both documents, 17 only in GBD and 4 only in JSM). In a random sample of $n=30$ scientists among the longer lists of signatories, five in GBD and three in JSM were top cited. By April 2021, only 19/47 key GBD signatories had personal Twitter accounts versus 34/34 of key JSM signatories; 3 key GBD signatories versus 10 key JSM signatories had $>50000$ Twitter followers and extraordinary Kardashian K-indices (363-2569). By November 2021, four key GBD signatories versus 13 key JSM signatories had $>50000$ Twitter followers.

Conclusions Both GBD and JSM include many stellar scientists, but JSM has far more powerful social media presence and this may have shaped the impression that it is the dominant narrative.

\section{INTRODUCTION}

The optimal approach to the COVID-19 pandemic has been an issue of major debate. Scientists have expressed different perspectives and many of them have also been organised to sign documents that outline overarching strategies. Two major schools of thought are represented by the Great Barrington Declaration $(\mathrm{GBD})^{1}$ and the John Snow Memorandum (JSM) ${ }^{23}$ that were

\section{Strengths and limitations of this study}

Citation impact metrics and Twitter followers can be measured with relatively high accuracy.

- The analysis focused primarily on the key signatories.

- Both citation indices and Twitter followers have limitations in face validity and construct validity as measures of impact.

released with a short time difference in the fall of 2020. Each of them had a core team of original signatories and over time signatures were collected for many thousands of additional scientists, physicians and (in the case of GBD) also citizens. ${ }^{4}$ A careful inspection is necessary to understand the differences (but also potential common points) of the two strategies. ${ }^{45}$ The communication of these strategies to the wider public through media and social media has often created confusion and tension. The communication includes what endorsing scientists state and how opponents describe the opposite strategy. Oversimplification, use of strawman arguments, and allusions of conflicts, political endorsements and ad hominem attacks can create an explosive landscape. ${ }^{4-9}$

Briefly, GBD is focused on targeted protection of high-risk individuals, while JSM considers that such a strategy may not be achievable. Much tension ${ }^{5-9}$ surrounds also the concept of herd immunity, where GBD declares that herd immunity is unavoidable eventually (much like gravity is unavoidable), while JSM stresses that aiming for herd immunity through natural infection is unethical. JSM proponents often accuse GBD proponents as urging the population to be infected, while GBD signatories deny this accusation. The two schools also tend to differ in terms of their approach towards lockdowns, seen in a far more negative light in GBD than in JSM.

It is often stated in social media and media, by JSM proponents in particular, that JSM is by far the dominant strategy and that very few 
scientists with strong credentials endorse GBD. ${ }^{6-9}$ GBD proponents are often characterised as fringe, arrogant and wrong by their opponents. ${ }^{6-9}$ However, are these views justified based on objective evidence on scientific impact or they reflect mostly perceptions created by social media and their uptake also by media?

Here, an analysis is being performed to try to evaluate the scientific impact and the social media visibility of the key signatories who have led the two strategies. Scientific impact is very difficult to evaluate in all its dimensions and no single number exists that can measure scientific excellence and scholarship. However, one can use citation metrics to objectively quantify the impact of a scientist's work in terms of how often it is used in the scientific literature. Adjustments for coauthorship patterns, relative contributions and scientific field need to be accounted for. ${ }^{10}$ Concurrently, an additional analysis evaluated the social media visibility of signatories, as denoted by Twitter followers.

\section{METHODS}

\section{Documents and signatories}

The two documents were retrieved online.${ }^{1-3}$ For the main analysis, the 47 original key signatories of the GBD who were listed on its original release online, and the 34 original key signatories who authored the first release of the JSM in a correspondence item published in the Lancet $^{3}$ were considered for in-depth citation analysis.

The two documents have been signed by many more signatories. As of 2 April 2021, the GBD site ${ }^{1}$ listed the following signature counts: 764172 concerned citizens, 13796 medical and public health scientists and 41895 medical practitioners. However, detailed data on names and affiliations were provided only on 443 medical and public health scientists. As of 25 November 2021, signature counts included 811461 concerned citizens, 15019 medical and public health scientists and 44541 medical practitioners. As of 2 April 2021, the JSM site ${ }^{2}$ listed 3600 names of signatories (expanded to 4200 as of 25 November 2021). The sets of 443 and 3600 names included also the original 47 and 34 key signatories, respectively. A random set of 30 names was selected from the 443 GBD names and from the 443 first-listed JSM names on 2 April 2021, acknowledging that the earlier listed names may be more likely to include highly cited, prominent scientists.

\section{Citation data}

Citation analyses used data on a validated composite citation indicator that considers six citation indicators (total citations, Hirsch H-index, coauthorship-adjusted Hm-index, total citations to single-authored papers, total citations to single or first-authored papers, total citations to single, first or last-authored papers). ${ }^{10-12}$ Existing databases were used that contain all authors who are in the top $2 \%$ of their scientific field based on career-long impact until the end of 2019 and based on impact in a recent single year (2019). ${ }^{12}$ Given that field assignment is not perfect, scientists who are in the top 100000 in the composite citation indicator across all scientists across all science are also included, regardless of whether they reach the top $2 \%$ in their specific field. Data were available including and excluding self-citations, as previously described, ${ }^{1112}$ and the latter are presented in the results, unless otherwise specified. The databases are compiled based on Scopus information on all authors who have at least five full papers (articles, reviews, conference papers) in their career ( $\sim 8$ million authors). Science is divided in 174 scientific fields according to the Science-Metrix classification that capitalises on the subject matter and journal venues where articles appear. ${ }^{13}$

\section{Twitter information}

For the 43 and 34 original key signatories, their names were searched on Google to identify personal Twitter accounts. Only accounts listed under their name were eligible, excluding group or institutional accounts from groups/institutions where they belonged or which they may have led. The number of followers of eligible Twitter accounts as of 2 April 2021 was recorded and an updated search was performed on 25 November 2021.

\section{Kardashian index calculations}

The Kardashian K-index ${ }^{14}$ is providing an impression on whether the Twitter footprint of a scientist is disproportionately high compared with the footprint of his/ her citation impact. It is calculated as the ratio of Twitter followers divided by $43.3 \mathrm{C}^{0.32}$, where $\mathrm{C}$ is the total citations received in one's career. The original publication ${ }^{14}$ defining the index used citations from Google Scholar. However, given that many signatories did not have Google Scholar pages and Google Scholar citations may be more erratic, Scopus citations (including self-citations) as of 2 April 2021 were used instead. Scopus citation counts may be slightly or modestly lower than Google Scholar citations, and this may lead to slightly higher K-index estimates, but the difference is probably small.

\section{Patient and public involvement}

There was no patient or public involvement in the study. No patients were evaluated in the study.

\section{RESULTS}

Top-cited scientists among the key GBD and JSM signatories Among the 47 original key signatories of GBD, 20, 19 and 21, respectively, were among the top-cited authors for their career impact, their recent single-year (2019) impact or either. Among the 34 original key signatories of JSM, 11, 14 and 15, respectively, were among the topcited authors for their career impact, their recent single year (2019) or either. The percentage of top-cited scientists is modestly higher for GBD than for JSM, but the difference is not beyond chance $(p>0.10$ for all three definitions). 
Table 1 Top-cited scientists among the key signatories of the Great Barrington Declaration (GBD) and John Snow Memorandum (JSM)

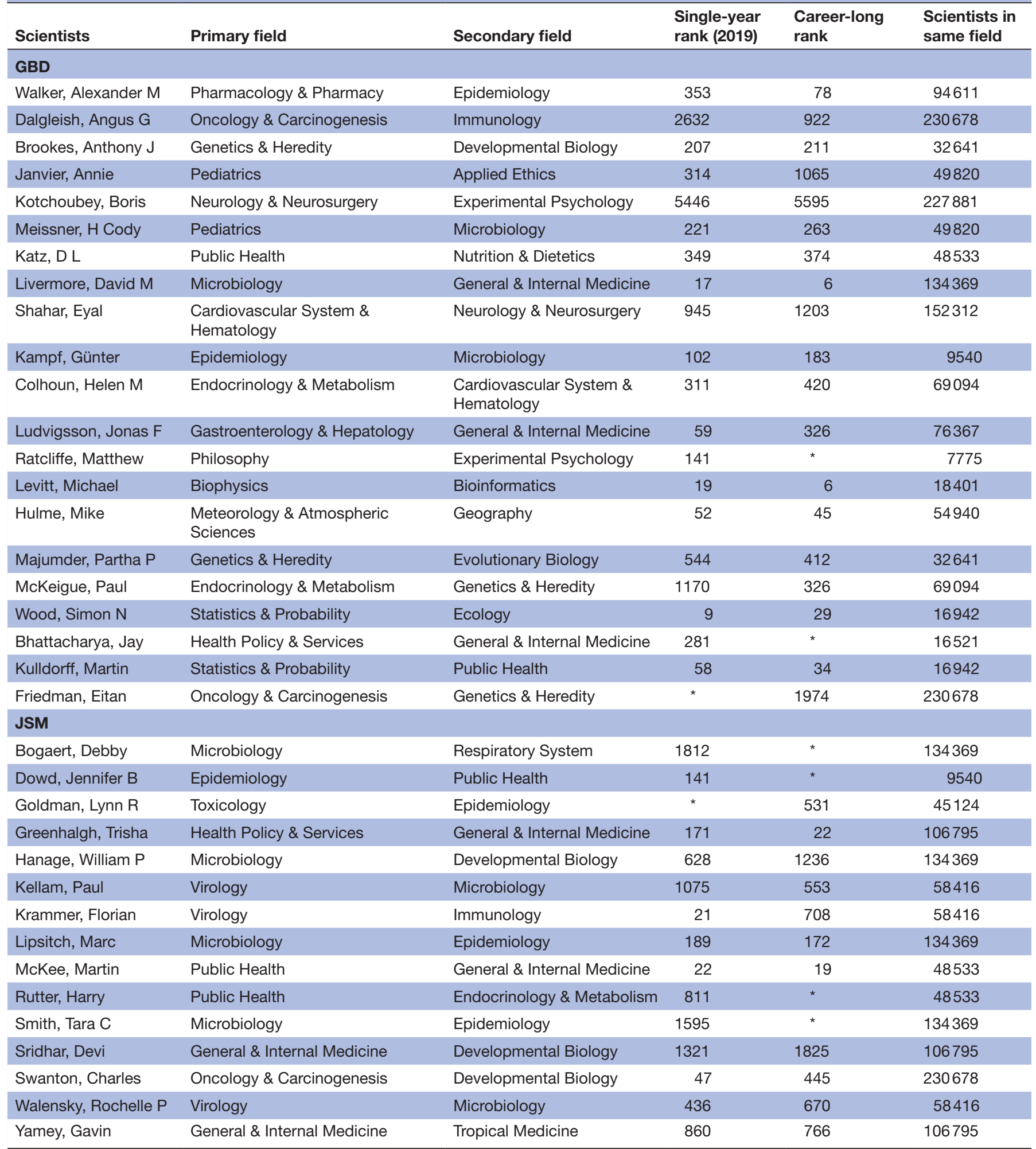

${ }^{*}$ Not in the top $2 \%$ of the field or top 100000 across all scientists and all science for the specific time frame.

Table 1 shows the 36 top-cited scientists from the key signatories of the two documents along with their primary and secondary scientific fields and their ranking among all scientists in their primary scientific field. As shown, when both the primary and secondary fields were considered, both documents had top-cited signatories representing nine fields (Developmental Biology, Endocrinology \& Metabolism, Epidemiology, General \& Internal Medicine, 
Health Policy \& Services, Immunology, Microbiology, Oncology \& Carcinogenesis, Public Health). Conversely 17 fields were represented only by key GBD signatories (Applied Ethics, Bioinformatics, Biophysics, Cardiovascular System \& Hematology, Ecology, Evolutionary Biology, Experimental Psychology, Gastroenterology \& Hepatology, Genetics \& Heredity, Geography, Meteorology \& Atmospheric Sciences, Neurology, Nutrition \& Dietetics, Pediatrics, Pharmacology \& Pharmacy, Philosophy, Statistics \& Probability) and four fields were represented only by key JSM signatories (Respiratory System, Tropical Medicine, Toxicology, Virology).

\section{Random samples of scientists from the longer list of signatories}

In a random sample of $n=30$ scientists among the longer list of GBD signatories, five were included in the databases of top-cited authors (in career-long and/or recent single-year citation impact), while this was true for $n=3$ of $30 \mathrm{JSM}$ controls, a difference not beyond chance $(p>0.10)$. These sampled scientists included three of the key signatories (Helen Colhoun and Michael Levitt (GBD) and Martin McKee (JSM)), and five additional ones (Dusko Ilic (Developmental Biology, Biochemistry \& Molecular Biology), Michael Jensen (Endocrinology \& Metabolism, General \& Internal Medicine), Guy Hutton (Tropical Medicine, Health Policy \& Services) in GBD; David Schwappach (General \& Internal Medicine, Health Policy \& Services) and Jose M Martin-Moreno (General \& Internal Medicine, Nutrition \& Dietetics) in JSM).

Excluding the key signatories, the proportions were $3 / 26$ and $2 / 27 \quad(p>0.10)$. The original key signatories were far more likely to include top-cited scientists in the GBD list $(21 / 47$ vs $3 / 26, p=0.004)$ and the same was true also for the JSM list $(15 / 34$ vs $2 / 27, \mathrm{p}=0.002)$.

\section{Personal Twitter accounts}

As of 2 April 2021, only 19/47 key GBD signatories had a retrievable personal Twitter account, while every single one of the 34 key signatories of JSM had a personal Twitter account $(\mathrm{p}<0.001)$. The median number of followers of the 34 JSM scientists was much larger than the median number of followers of the 47 GBD scientists (31600 vs 0 , $\mathrm{p}<0.001$, figure 1 ).

Only 4/47 GBD signatories versus $17 / 34$ JSM signatories had over 30000 Twitter followers (3/47 vs 10/34 for signatories with over 50000 Twitter followers). Twitter and citation data, and inferred Kardashian K-indices for the scientists with $>50000$ followers appear in table 2. The values of K-index in these scientists were extraordinarily high (363-2569).

An updated search for Twitter accounts and followers on 25 November 2021 found that 22/47 key GBD signatories versus $34 / 34$ key JSM signatories had a retrievable Twitter account $(\mathrm{p}<0.001)$. The median number of followers was 0 vs $34600(\mathrm{p}<0.001)$. The number of key signatories with $>50000$ followers was 13 vs 4 .

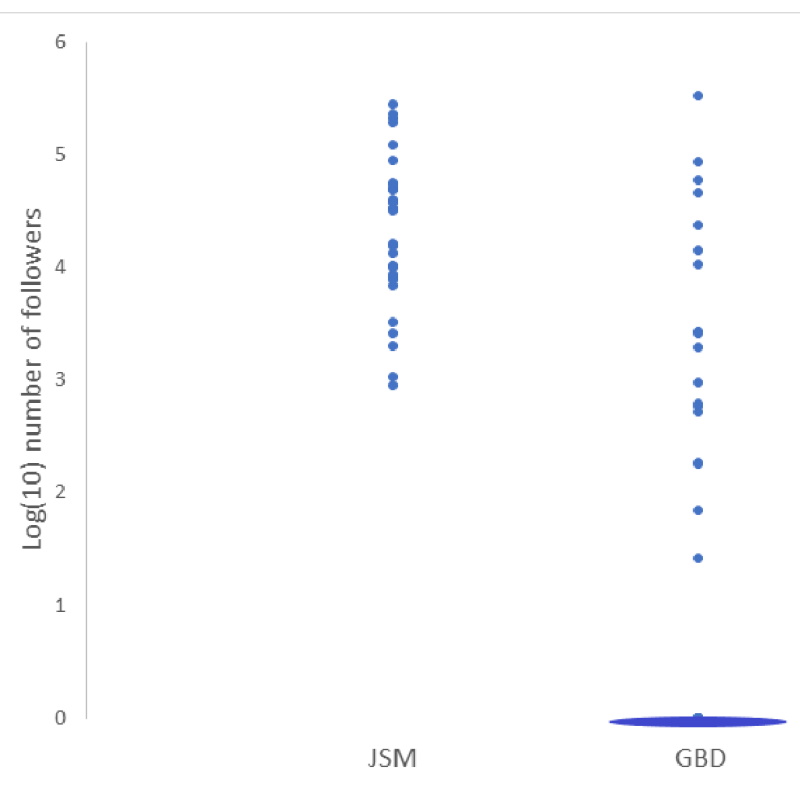

Figure 1 Number of Twitter followers of John Snow Memorandum (JSM) and Great Barrington Declaration (GBD) key signatories in April 2021. Twenty-eight of the 47 GBD signatories had no identified personal Twitter accounts.

\section{DISCUSSION}

An analysis of citation and social media impact of GBD and JSM signatories shows that both documents have been signed by many leading stellar scientists with very high citation impact in the scientific literature. Random sample data on the longer list of signatories suggest that, expectedly, the longer lists are less thickly populated with extremely highly cited scientists. The total number of top-cited scientists cannot be compared for the two documents because the GBD site does not provide details on all the signatories and signatures are still verified and vetted. Thus, it is unclear whether the much larger total number of signatures in GBD would also translate to a substantially larger total number of top-cited scientists endorsing it as compared with JSM. Regardless, GBD is clearly not a fringe minority report compared with JSM, as many social media and media allude. ${ }^{6-9}$ GBD may be a more commonly espoused narrative than the JSM narrative among most cited scientists. Acknowledging uncertainty given the fragmentary nature of the presented names of signatories, it is safe to conclude that both documents have been endorsed by many scientists who are very influential in the scientific literature.

Conversely, the two cohorts of key signatories have a stark difference in Twitter follower counts. The majority of key GBD signatories have no personal Twitter account that could be readily identified. While it is possible that some accounts might have been missed (eg, if not directly named after the individual scientist's names), the difference is so major that it is very unlikely to be a data retrieval artefact. Even among those GBD signatories who do have Twitter accounts, very few have a high number of followers. The key JSM signatories have a 
Table 2 Key signatories of John Snow Memorandum (JSM) or Great Barrington Declaration (GBD) with over 50000 Twitter followers as of April 2021: citation impact, $\mathrm{H}$-index and $\mathrm{K}$-index

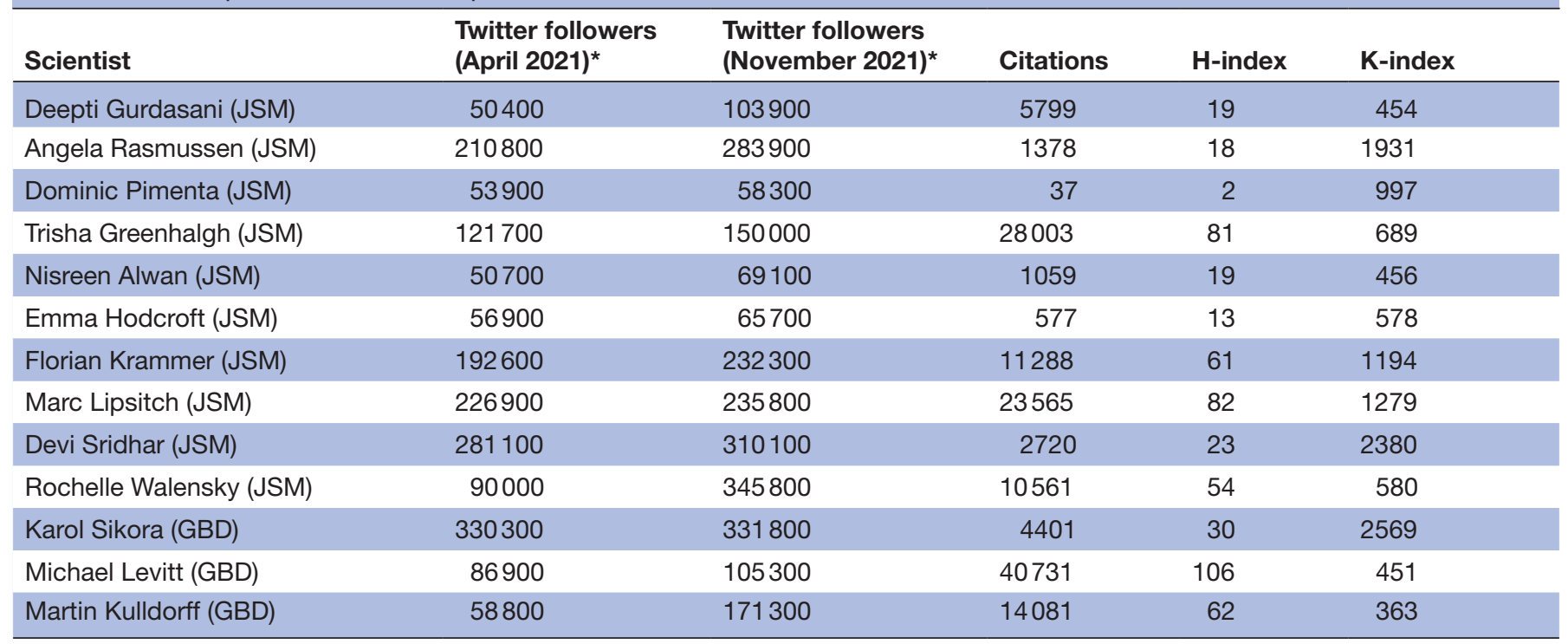

Only scientists with $>50000$ Twitter followers as of April 2021 are shown in the table. As explained in the asterisk footnote below, by November 2021, there were three more John Snow Memorandum key signatories (Isabella Eckerle, Zoe Hyde, Viola Priesemann) who had increased their Twitter followers to $>50000$ and one more Great Barrington Declaration signatory (Jay Bhattacharya) who had acquired a Twitter account in the meanwhile and had also exceeded 50000 Twitter followers. H-indices in November 2021 were 26 for Isabella Eckerle, 22 for Zoe Hyde, 21 for Viola Priesemann and 37 for Jay Bhattacharya.

${ }^{*}$ Twitter followers for other key signatories in April 2021 and (in parenthesis) in November 2021: Rochelle A. Burgess 3281 (4504), Simon Ashworth 8246 (9124), Rupert Beale 15500 (19 200), Nahid Bhadelia 33700 (39 400), Debby Bogaert 2574 (3030), Jenn Dowd 6933 (7221), Isabella Eckerle 48800 (61 200), Lynn R Goldman 909 (922), Adam Hamdy 10100 (12 000), William Hanage 39500 (48 700), Zoe Hyde 39100 (55 300), Paul Kellam 1069 (1107), Michelle Kelly-Irving 10200 (10 500), Alan McNally 16300 (19 300), Martin McKee 33800 (40 300), Ali Nouri 31600 (34 600), Viola Priesemann 37700 (54 900), Harry Rutter 8714 (8859), Joshua Silver 13300 (15 800$)$, Charles Swanton 7724 (8721), Gavin Yamey 10200 (26 100), Hisham Ziauddeen 2025 (9795) for JSM; and Andrius Kavaliunas 182 (3479), Ariel Munitz 952 (1013), David Katz 46000 (46 000), Eyal Shahar 2619 (6152), Gabriela Gomes 10500 (14 400), Gerhard Krönke 69 (117), Jonas Ludvigsson 2693 (7140), Lisa White 586 (642), Matthew Strauss 14200 (22 700), Rajiv Bhatia 187 (1525), Salmaan Keshavjee 1955 (2213), Simon Thornley 520 (1207), Sylvia Fogel 614 (3405), Udi Qimron 2695 (4374), Yaz Gulnur Muradoglu 26 (39) for GBD. No personal Twitter accounts were found for the remaining GBD signatories in April 2021, but three of them had detectable Twitter accounts in searches done in November 2021 (Ellen Townsend 18400 followers, Stephen Bremner 15 followers, Jay Bhattacharya 80800 followers).

very large number of followers in highly active personal Twitter accounts. The most visible Twitter owners include some of the most cited scientists in the analysed cohorts (Trisha Greenhalgh, Marc Lipsitch, Florian Krammer, Rochelle Walensky, Michael Levitt, Martin Kulldorff, Jay Bhattacharya) and others who have little or no impact in the scientific literature, but are highly remarkable and laudable for their enthusiastic activism (eg, Dominic Pimenta).

Previous work that introduced the Kardashian K-index stated that K-index values above 5 suggest an overemphasis of social media versus scientific literature presence and called such researchers 'Science Kardashians'. ${ }^{14}$ This characterisation has not caught up with evolutions in the last few years. Many signatories, especially of JSM, have extraordinarily high K-index, with values in the hundreds and thousands. However, one should account that the volume of Twitter users and followers has increased markedly since the K-index was first proposed, even before the COVID-19 pandemic and even for specialists in disciplines that are not very likely to attract massive social media interest (eg, urology). ${ }^{15}$ As COVID-19 has attracted tremendous social media attention, Kardashian K-indices are skyrocketing. While no past data were available for the number of followers of the analysed scientists preCOVID, anecdotal experience suggests that many, if not most, saw their followers increase tremendously during the pandemic. Substantial increases were documented even in the short 7-month interval between April and November 2021.

The massive advent of social media contributes to a rampant infodemic ${ }^{16-18}$ with massive misinformation circulating. If knowledgeable scientists can have strong social media presence, massively communicating accurate information to followers, the effect may be highly beneficial. Conversely, if scientists themselves are affected by the same problems (misinformation, animosity, loss of decorum and disinhibition, among others) ${ }^{19} 20$ when they communicate in social media, the consequences may be negative.

The current analysis has several limitations. The analysis focused primarily on the key signatories and only a small sample of the other signatories from the longer lists was perused. More importantly, both citation indices 
and Twitter followers have limitations in face validity and construct validity as measures of impact. A lesser concern is also that both can have errors of measurement, as discussed below. The most important caveat is that scientific impact is difficult to capture fully with any quantitative metrics.

Specifically, citation indices do not capture necessarily all aspects of scholarship. ${ }^{21}$ The standardised, validated composite index used here overcomes many of the limitations of crude citation counting, but it is still not perfect. For detailed description of the methods (and their validation) involved in selecting the top-cited scientists across disciplines, one is referred to the background work done to generate the lists of top-cited scientists. ${ }^{10-12}$ Precision and recall (author disambiguation in assigning papers) are not perfect in Scopus, and some authors may have underestimated or overestimated citation metrics, but large errors are very uncommon. ${ }^{22}$ Publications in Scopus author profiles have $98.1 \%$ average precision (ratio of publications correctly assigned to an author) and $94.4 \%$ average recall (ratio of an author's papers captured compared with a gold set). ${ }^{22}$ The precision for citation linking in Scopus is measured at 99.9\% and the recall is $98.3 \%{ }^{22}$ Regardless, of the high technical accuracy of these citation data, many scientists who are not included in the lists of top-cited scientists may be at least as outstanding as those who are included, and many dimensions of scholarship, social responsibility and broader impact may be missed by citation indices. ${ }^{23}$

Twitter follower counts are practically impossible to see as measures of excellence in the absence of context. Social media impact may not necessarily be positive, and massive misinformation and despicable behaviour may still generate huge follower lists. Personal Twitter accounts are easy to match against a specific person, provided that the identity of that person can be discerned in Twitter. One cannot exclude the possibility that some of the people for which no Twitter account could be identified may have a pseudonymous Twitter account that hides their true identity. However, in this case, they are not using their personal credentials and overall expertise profile to support the credibility and validity of their Twitter content. Moreover, some academics or researchers may not have personal Twitter accounts, but the centre, institute or other organisation they work in may have some social media presence. The current analysis did not aim to capture these Twitter accounts, since, by definition, they are not personal accounts, but serve a very different role.

Acknowledging these caveats, the data suggest that the massive superiority of JSM over GBD in terms of Twitter firepower may have helped shape the narrative that it is the dominant strategy pursued by a vast majority of knowledgeable scientists. This narrative is clearly contradicted by the citation data. The Twitter superiority may also cause, and/or reinforce also superiority in news coverage. In a darker vein, it may also be responsible for some bad publicity that GBD has received, for example, as evidenced by plain Google searches online or searches in Wikipedia pages for GBD, its key signatories or even for other scientists who may espouse some GBD features, for example, scepticism regarding the risk-benefit of prolonged lockdowns. Smearing, even vandalisation, is prominent for many such Wikipedia pages or other social media and media coverage of these scientists. This creates a situation where scientific debate becomes vitriolic, and censoring (including self-censoring) may become prominent. Perusal of the Twitter content of JSM signatories and their op-eds suggests that some may have sadly contributed to GBD vilification. ${ }^{24}$

A major point of attack has been alleged conflicts of interest. However, GBD leaders have repeatedly denied conflicts of interest (see also the site of $\mathrm{GBD}^{1}$ ). Key JSM signatories appropriately and laudably disclosed upfront all potential conflicts of interest in their original letter publication in the Lancel; the long list is available in public. ${ }^{3}$ Based on this list, it is possible that JSM leaders have more conflicts than GBD leaders, but the social media superiority of JSM controls also the narrative surrounding conflicts. A similar vitriolic attack has been launched against the American Institute of Economic Research that offered the venue for hosting the launch of GBD. ${ }^{24}$ Experimental studies show that mentioning conflicts may have the same degree of negative impact as attacks on the empirical basis of the science claims; allegations of conflict of interest are as influential as allegations of outright fraud, when the value of scientific evidence is appraised. ${ }^{25}$ Non-scientists' trust is eroded by allusions of conflicts of interest, while it is not affected much by perception of scientific (in) competence (which is also impossible for a non-expert to appraise). ${ }^{25}{ }^{26} \mathrm{In}$ good faith, reporting of potential conflicts of interest should be encouraged and transparency maximised. However, spurious allegations of hidden agendas and conflicts should not become a weapon for invalidating one or the other document. While exceptions may exist, probably the vast majority of scientists who signed either document simply had good intentions towards helping in a major crisis.

Number of signatures and/or scientific or other impact and visibility of the signatories does not prove that a document is correct. While such petitions are becoming increasingly common in science, ${ }^{27}$ it is erroneous to imagine that scientific knowledge should be decided by crude, expertise-weighted, citation-weighted or Twitter-weighted vote counting. ${ }^{28}$ Moreover, while both documents include a massive number of stellar scientists, the vast majority of the most influential scientists have not signed either document. Some of them may be embarrassed to sign given the adversarial, smearing environment that has emerged. Alternatively, many probably see that neither document contains the perfect truth. And, of course, many scientists generally abstain from signature collections.

Finally, while the data analysed here are limited to a relatively small number of top-cited scientists, the evaluation of the key scientific fields where these scientists publish offers some interesting hints. Both GBD and JSM include top signatories in disciplines such as epidemiology, public health and general and internal medicine 
that are core pertinent fields in the pandemic. GBD has more diversity in field expertise and includes top signatories in quantitative disciplines such as statistics and bioinformatics, as well as paediatrics and ethics that are not represented among key JSM signatories, while JSM has superior representation in virology. These patterns may be due to chance given the relatively small sample analysed, and given the many thousands of additional signatories, these fields may well be represented in the longer lists. However, these patterns could also reflect some genuine differences in overall perspective between the two strategies. For example, GBD focuses more on the potential multifaceted collateral damage of lockdowns and on prioritising quantitative assessment of risk (where children and young people have far lower risk than elderly, vulnerable people), ${ }^{29}$ while JSM depends more heavily on basic virology expertise. Given the magnitude of the COVID-19 crisis, it is important to ensure that scientific disciplines can collaborate dispassionately and that different views can be juxtaposed and integrated. GBD and JSM may have more in common than it is often thought. Critical differences between them should be probed with rigorous science rather than defended on partisan grounds and with social media warfare.

Contributors JPI conceptualised the original idea, collected the data, analysed the data and wrote the manuscript. JPI is guarantor.

Funding The author has not declared a specific grant for this research from any funding agency in the public, commercial or not-for-profit sectors.

Competing interests The author has signed neither of the two documents and has many friends, collaborators and other people who he knows and he admires among those who have signed each of them. JPI has previously published that he is very skeptical about signature collection for scientific matters (BMJ 2020;371:m4048). He has no personal social media and he believes that the fact that his citation indices are extremely high only proves (when compared against his self-acknowledged vast ignorance) that these indices can occasionally be very unreliable. JPI congratulates all the thousands of signatories (of both documents) for their great sense of social responsibility.

Patient and public involvement Patients and/or the public were not involved in the design, or conduct, or reporting, or dissemination plans of this research.

Patient consent for publication Not applicable.

Ethics approval This study does not involve human participants.

Provenance and peer review Not commissioned; externally peer reviewed.

Data availability statement All data relevant to the study are included in the article. Data are available in a public, open access repository. All the data are in the manuscript and tables and additional detail on citation data are available in publicly deposited data sets in Mendeley.

Open access This is an open access article distributed in accordance with the Creative Commons Attribution Non Commercial (CC BY-NC 4.0) license, which permits others to distribute, remix, adapt, build upon this work non-commercially, and license their derivative works on different terms, provided the original work is properly cited, appropriate credit is given, any changes made indicated, and the use is non-commercial. See: http://creativecommons.org/licenses/by-nc/4.0/.

\section{ORCID iD}

John P Ioannidis http://orcid.org/0000-0003-3118-6859

\section{REFERENCES}

1 Great Barrington Declaration. Available: https://gbdeclaration.org/ [Accessed 3 Apr 2021].
2 John snow memorandum. Available: https://www.johnsnowmemo. com/ [Accessed 3 Apr 2021].

3 Alwan NA, Burgess RA, Ashworth S, et al. Scientific consensus on the COVID-19 pandemic: we need to act now. Lancet 2020;396:e71-2.

4 Lenzer J. Covid-19: Experts debate merits of lockdowns versus "focused protection". BMJ 2020;371:m4263.

5 Burki TK. Herd immunity for COVID-19. Lancet Respir Med 2021;9:135-6.

6 Gump BB. The great Barrington declaration: when arrogance leads to Recklessness. Available: https://www.usnews.com/news/healthiestcommunities/articles/2020-11-06/when-scientists-arrogance-leadsto-recklessness-the-great-barrington-declaration [Accessed $2 \mathrm{Apr}$ 2021].

7 Archer SL. 5 failings of the Great Barrington Declaration's dangerous plan for COVID-19 natural herd immunity. Available: https:// theconversation.com/5-failings-of-the-great-barrington-declarationsdangerous-plan-for-covid-19-natural-herd-immunity-148975 [Accessed 2 Apr 2021].

8 Mandavilli A. A viral theory cited by health officials draws fire from scientists. Available: https://www.nytimes.com/2020/10/19/health/ coronavirus-great-barrington.html [Accessed 2 Apr 2021].

9 Lenzer J, Brownlee S. The COVID-19 science wars. scientific American. Available: https://www.scientificamerican.com/article/thecovid-science-wars1/ [Accessed 2 Apr 2021].

10 loannidis JPA, Klavans R, Boyack KW. Multiple citation indicators and their composite across scientific disciplines. PLOS Biol 2016;14:e1002501.

11 loannidis JPA, Baas J, Klavans R, et al. A standardized citation metrics author database annotated for scientific field. PLOS Biol 2019;17:e3000384.

12 Ioannidis JPA, Boyack KW, Baas J. Updated science-wide author databases of standardized citation indicators. PLOS Biol 2020;18:e3000918.

13 Archambault E, Beauchesne $\mathrm{OH}$, Caruso J. Towards a multilingual, comprehensive and open scientific Journal ontology. Proceedings of the 13th International Conference of the International Society for Scientometrics and Informetrics (ISSI), Durban, South Africa, 2011:66-77.

14 Hall N. The Kardashian index: a measure of discrepant social media profile for scientists. Genome Biol 2014;15:424.

15 Chandrasekar T, Goldberg H, Klaassen Z, et al. Twitter and academic urology in the United States and Canada: a comprehensive assessment of the Twitterverse in 2019. BJU Int 2020;125:173-81.

16 Ahmed N, Shahbaz T, Shamim A, et al. The COVID-19 Infodemic: a quantitative analysis through Facebook. Cureus 2020;12:e11346.

17 Cinelli M, Quattrociocchi W, Galeazzi A, et al. The COVID-19 social media infodemic. Sci Rep 2020;10:16598.

18 Zarocostas J. How to fight an infodemic. Lancet 2020;395:676.

19 Voggeser BJ, Singh RK, Göritz AS. Self-control in online discussions: disinhibited online behavior as a failure to recognize social cues. Front Psychol 2017;8:2372.

20 Cheng J, Bernstein M, Danescu-Niculescu-Mizil C, et al. Anyone can become a troll: causes of Trolling behavior in online discussions. CSCW Conf Comput Support Coop Work 2017;2017:1217-30.

21 Hicks D, Wouters P, Waltman L, et al. Bibliometrics: the Leiden manifesto for research metrics. Nature 2015;520:429-31.

22 Baas J, Schotten M, Plume A, et al. Scopus as a curated, highquality bibliometric data source for academic research in quantitative science studies. Quant Sci Stud 2020;1:377-86.

23 Rice DB, Raffoul H, loannidis JPA, et al. Academic criteria for promotion and tenure in biomedical sciences faculties: cross sectional analysis of international sample of universities. BMJ 2020;369:m2081.

24 Greenhalgh T, McKee M, Kelly-Irving M. The pursuit of herd immunity is a folly - so who's funding this bad science? Guardian 2021.

25 Barnes RM, Johnston HM, MacKenzie N, et al. The effect of AD hominem attacks on the evaluation of claims promoted by scientists. PLoS One 2018;13:e0192025.

26 Mayer RC, Davis JH, Schoorman FD. An integrative model of organizational trust. Acad Manag Rev 1995;20:709-34.

27 Hardwicke TE, loannidis JPA. Petitions in scientific argumentation: dissecting the Request to retire statistical significance. Eur J Clin Invest 2019;49:e13162.

28 loannidis JP. Scientific petitions and open letters in the era of covid-19. BMJ 2020;371:m4048.

29 Smith GD, Spiegelhalter D. Shielding from covid-19 should be stratified by risk. BMJ 2020;369:m2063. 
Correction: Citation impact and social media visibility of

Great Barrington and John Snow signatories for

COVID-19 strategy

Ioannidis JP. Citation impact and social media visibility of Great Barrington and John Snow signatories for COVID-19 strategy. BMJ Open 2022;12:e052891. doi: 10.1136/ bmjopen-2021-052891.

1. The methods section does not indicate the statistical tests being used. The statistical tests are: (i) the Fisher's exact test for $2 \times 2$ tables (ii) the Mann-Whitney $\mathrm{U}$ test for two groups.

2. The Kardashian K-index was originally presented in satirical tone in an article, ${ }^{1}$ but has been used in numerous studies as a measure of an author's scholarly output compared to their social media presence.

3. The competing interests declaration of the author has been disputed, particularly the author's relationships to researchers closely linked to the Great Barrington Declaration, most notably Jay Bhattacharya and Scott Atlas. Please see the rapid responses to the article for the criticisms and the author's response. The author has now provided a more detailed statement relating to his professional collaborations:

As of February 2022, the 443 signatories from GBD included four scientists with whom I have co-authored, and three with Stanford affiliation. The respective first 443 signatories of JSM included five scientists with whom I have co-authored, and 15 with Stanford affiliation. I have co-authored COVID-19 scientific papers with both GBD and JSM signatories (more with the latter). I have more close ongoing collaborators and friends in JSM than GBD. According to Scopus I have 6590 co-authors and probably>200 have signed GBD or JSM. I have learnt from both JSM and GBD colleagues and I thank them all for sharing their wisdom. Some readers ruminated on potential relationships specifically with Jay Bhattacharya (JB) and Scott Atlas (SA), so I provide more in-depth details: I have co-authored five papers with JB, talked with him and met in person several times, and enjoyed dinner together once (in April 2022). Comparatively, with several JSM signatories I have co-authored more papers (up to 19), talked and met more often and shared more meals. An interview (https://www.youtube.com/watch?v=xOu8jWMluSk) highlights my agreements and disagreements with JB. I have not co-authored with SA, I have talked a few times with him, but haven't met in person yet. I have interacted with several thousand people more than with SA. I am among several thousands of Stanford faculty and staff who did not sign an open denouncement letter against SA; the approximately 100 who signed include some of my best friends and collaborators. I wish people with opposing views could meet and discuss dispassionately 1 day, and I offer to moderate such discussions. I thank everyone who made well-intentioned contributions to the COVID-19 crisis.

Open access This is an open access article distributed in accordance with the Creative Commons Attribution Non Commercial (CC BY-NC 4.0) license, which permits others to distribute, remix, adapt, build upon this work non-commercially, and license their derivative works on different terms, provided the original work is properly cited, appropriate credit is given, any changes made indicated, and the use is non-commercial. See: http://creativecommons.org/licenses/by-nc/4.0/.

(c) Author(s) (or their employer(s)) 2022. Re-use permitted under CC BY-NC. No commercial re-use. See rights and permissions. Published by BMJ.

BMJ Open 2022;12:e052891corr1. doi:10.1136/bmjopen-2021-052891corr1

Check for updates

\section{REFERENCE}

1 Hall N. The Kardashian index: a measure of discrepant social media profile for scientists. Genome Biol 2014;15:424. 